\title{
Incomplete or Inadequate Connection
}

National Cancer Institute

\section{Source}

National Cancer Institute. Incomplete or Inadequate Connection. NCI Thesaurus. Code C133626.

Problem associated with a partial linking of the device whereby the device may appear to be connected however only a partial, intermittent or no transfer of liquid, gas, electricity, or information can be accomplished. 